\title{
Risk Factors with Intimate Partner Violence among Women Seeking Emergency Care
}

\author{
Darcia Pratt-Eriksson ${ }^{1,2 *}$, Elisabeth Dahlborg-Lyckhage ${ }^{3}$, Ingegerd Bergbom ${ }^{1}$ \\ ${ }^{1}$ Institute of Health and Care Sciences, Sahlgrenska Academy, University of Gothenburg, Gothenburg, Sweden \\ ${ }^{2}$ Neurological Department, Karolinska University Hospital, Stockholm, Sweden \\ ${ }^{3}$ University West, Trollhättan, Sweden \\ Email: *darciapratt@gmail.com
}

How to cite this paper: Pratt-Eriksson, D., Dahlborg-Lyckhage, E. and Bergbom, I. (2017) Risk Factors with Intimate Partner Violence among Women Seeking Emergency Care. Open Journal of Nursing, 7, 86-97.

http://dx.doi.org/10.4236/ojn.2017.71008

Received: November 27, 2016

Accepted: January 16, 2017

Published: January 19, 2017

Copyright (C) 2017 by authors and Scientific Research Publishing Inc. This work is licensed under the Creative Commons Attribution International License (CC BY 4.0).

http://creativecommons.org/licenses/by/4.0/

\begin{abstract}
Background: Identifying women at risk for violence caused by intimate partner violence is difficult in connection with visits at emergency department. Aims and objectives: The aim of this study was to explore and describe risk factors of IPV reported by women in connection with seeking emergency care, Design: This study is part of a larger study using an explorative and comparative design. Method: Based upon data from a questionnaire and some demographic data, 82 women who reported to have experienced intimate partner violence answered the Danger Assessment Scale. Results: The results showed that the violence escalated in frequency and severity when a weapon such as a knife or gun was used to harm the women. When the abuser used narcotics and threatened the woman with a weapon, the risk of being injured increased. The odds for being threatened to death when the abuser was reported to use narcotics and illegal drugs was about thirteen times higher compared to the case when the abuser was not using narcotics. Other life threatening factors were discovered such as the man's capability of killing the woman. Conclusion: By using a questionnaire about the violence, healthcare personnel can identify women who are at risk of being severely injured or killed. By identifying these women, one can take action to provide for their safety. Relevance to Clinical Practice: Using the Danger Assessment instrument can facilitate health care personnel's ability at emergency departments to identify women at risk for lethal violence.
\end{abstract}

\section{Keywords}

Intimate Partner Violence, Lethal Violence, Abuse Women, Nursing Care, Emergency Care

\section{Introduction}

Intimate Partner violence (IPV) is a multifaceted global problem creating prob- 
lems for the abused woman and her family [1] [2]. According to research [3] in Finland, intimate-partner homicides (intentional and unintentional murder) made up a larger percentage of homicides against women than in Sweden or the Netherlands. In spite of this, the percentage of female victims killed outside close relations was almost the same in Finland (20 per cent) and in Sweden (24 per cent), and it was possible that it was more or less the same in the Netherlands. In Sweden an average of sixteen women are killed by a man who is involved in an intimate relationship with the victim at the time of the offence, or has been involved in such a relationship with the victim at some point prior to the offence [4]. According to Campbell et al. [5] and Sabri et al. [6], women were murdered by intimate partners, husbands, lovers, ex-husbands and ex-lovers more often than by any other category of killer. The most severe health consequence of intimate partner violence is homicide (manslaughter and murder), causing more than half the homicides to women in the United States each year [7]. It is stated that, two women are murdered, on average, each day in Guatemala and is concluded that a woman is killed every eight hours in South Africa by an intimate partner [8] [9]. Identifying IPV in emergency care is challenging. A vital question is if nurses and physicians at emergency departments have tools and possibilities for identifying IPV and risk for lethal violence and thus ability to take actions that might prevent homicides. Minimal research concerns risk factors in relation to IPV, the severity and occurrence of the violence among women seeking care at an emergency department. Sabri et al. [6] indicate that abused women presenting with severe injuries in health care settings are likely to be at high risk for being killed. This study focused on exploring and describing risk factors of violence among women who reported intimate partner violence in connection with seeking emergency care.

\section{Background}

Identifying and assessing the risk of homicide among women is not easy. Despite IPV has received increasing international attention as a public health and human rights concern, the killing of women is still not well understood. Research has noted the importance of assessing the risk of IPV (Campbell [5] and Dobash [10]). Campbell [5] stated that several risk factors have been associated with increased risk of homicides of women and men in violent relationships. Another factor, which may be of importance, is the perpetrator's mental health. Rying [4] explains that it is very common that the perpetrators, who kill, suffer from some form of mental illness or other mental disorder. Eighty per cent of the men who kill women in the context of an intimate partner relationship suffer from mental disorders such as depression and emotional problems. It is however not only the violent persons that may suffer from mental disorder, the women's health is also negatively affected. Several studies [4] [5] [10] have documented increased risk for a number of adverse physical, mental, reproductive, sleep-disorders, selfharm and other health outcomes among those who have experienced intimate partner violence and sexual violence. Previous research has shown that many 
women suffer from Post-Traumatic Stress Disorder (PTSD), anxiety and depression [11] [12]. These mental health effects of chronic and severe violence are, in turn, risk factors for suicidal ideation [9] [13] [14] [15]. It can be discussed if increasing severe violence and as warning signals. Questions that concern risk factors may also help women to realize risks for being lethal injured. Such questions may also facilitate communications about their life situation, health and the violent relationship when women are seeking care for their injuries or health problems at emergency departments. Caretta [16] suggests that women's health problems in relation to IPV should be addressed by using screening and support. It is known that health care professionals find it difficult to ask patients about domestic violence and it is possible that these types of questionnaires will help nurses to identify and address the issue of IPV [17]. Research conducted at Swedish psychiatric services [18] has shown that $63 \%$ of women seeking such care reported being abused and in a review by [19], about $30 \%$ of the women seeking care at psychiatric outpatient clinics reported abuse. However, very little is known about how to identify risk for lethal violence and the risk of being killed among women in Sweden who are seeking care at emergency departments. By identifying this, actions can be taken by the health care personnel, which might prevent homicide.

The aim of this study was to explore and describe risk factors of IPV reported by women in connection with seeking emergency care. The following questions guided this study:

What IPV risk factors do women who were seeking care an emergency department report? Are there any relationships between these risk factors?

\section{Methods}

\subsection{Study Design}

This study is part of a larger study using an explorative and comparative design [20]. During September 2008 and June 2009, 300 women who were seeking treatment at an Emergency Department (ED) at a hospital in Sweden $(40,000$ inhabitants) and who fulfilled the inclusion criteria, were consecutively invited to participate in the study by answering two questionnaires. These were a Swedish version of Abuse Assessment Scale (AAS) [21] and a translated version of Danger Assessment Scale (DAS) [22]. Eligible subjects were female who were at least 18 years old, understood Swedish or English and had cognitive ability to answer questions. Of these 300 women, 234 (78\%) answered the AAS and DAS and of these 82 women reported experiences of IPV sometime during their lifetime. In this study, the findings from DAS will be reported.

Two trained female nurses at the ED, with experience of caring for abused women, invited the women by giving them information about the study and that participation included answering two questionnaires. Their right to anonymity and that their participation was voluntary. After acceptance, an envelope and the questionnaires were handed over and the women were encouraged to answer the questionnaire and put it in the envelope and seal it. This information and pro- 
cedure was performed face to face with no other persons present in the room. The instrument used in this study is the DAS instrument designed and developed by Jacqueline Campbell to assess likelihood of lethality or near lethality occurring in a case of intimate partner violence. The questionnaire is scored dichotomously at yes/no responses [5] [22] [23]. The DAS was scored by counting the "yes" responses, with a higher number indicating more risk in the relationship. The DAS version 2004, which consists of 20 items, was translated from English to Swedish (see supplement DAS) by three native Swedish spoken researchers who were familiar with English language. The translated text was then translated back to English by three other researchers, familiar with both Swedish and English. There were no differences found concerning the introductory text and the instructions. The authors decided to not only to refer to the gender "he" as in the original version, but use both genders he/she as some women may experience violence in lesbian relationships (see Box 1). The first question about frequency and severity during the last year was reworded and changed into two separate questions: Has the physical violence increased in frequency during the last year? And has the physical violence become more violent and severe during the last year? Additionally, other questions were added "Is he/she violent to your children? And is he/she violent outside home? Has he/she ever threatened to commit suicide?" Construct validity for this instrument has been derived from the original instrument. The relevancy of the changes and new questions were discussed with J. Campbell. Reliability was not established for this instrument; the questions are similar. Thus the Swedish version consists of 25 questions. We decided to weight all variables the same and only count the "yes" answers: Less than 8 means danger, 8 to 13 means increased danger, 14 to 17 means severe danger and 18 to 25 means extreme danger. However, in accordance with Campbell's statements each variable/factor where the woman had answered "yes" should be seen as a danger for her life. In conjunction with the data collection of the DAS, some demographic data was also collected. These data were: women's age, number of children living at home, education, employment or not, salary/ year and marital status.

\subsection{Data Analysis}

Descriptive statistics, such as median (md), mean and standard deviation (SD), and analysis were applied using Statistical Package for the Social Sciences (SPSS version 21). Demographic data and variables from the DAS were compared using non-parametric test. Fisher's Exact Test and Chi square test were used to test the significance of proportions to compare frequencies. For estimating the probability of an event to occur [24] Odds Ratio (OR) was calculated, with $95 \%$ confidence interval (CI).

Ethical permission was granted earlier from the Ethical committee in Gothenburg as this study is part of a larger study. The women were given oral and written information about the study, and were informed of their rights to anonymity, rights to confidentiality and their rights to termination of the study. 
BOX 1. Danger assessment. A modified version for Swedish population [23].

Several risk factors have been associated with increased risk of homicides (murders) of women and men in violent relationships. We cannot predict what will happen in your case, but we would like you to be aware of the danger of homicide in situations of abuse and for you to see how many of the risk factors apply to your situation.

Using the calendar, please mark the approximate dates during the past year when you were abused by your partner or ex-partner. Write on that date how bad the incident was according to the following scale:

1) Slapping, pushing; no injuries and/or lasting pain

2) Punching, kicking; bruises, cuts, and/or continuing pain

3) "Beating up"; severe contusions, burns, broken bones

4) Threat to use weapon; head injury, internal injury, permanent injury, miscarriage, choking

5) Use of weapon; wounds from weapon

(If any of the descriptions for the higher number apply, use the higher number.)

Mark Yes or No for each of the following.

("He" refers to your husband, partner, ex-husband, ex-partner, or whoever is currently physically hurting you.)

Yes/No

1) Has the physical violence increased in severity?.

2) Has the violence increase in frequency over the past year?.............

3) Is there a gun in the home?..

4) Does your partner own a gun?.

5) Have there been threats with a weapon/the use of weapon within the last year?.

6) Has he/she ever used a weapon against you or threatened you with a lethal weapon?

(If yes, was the weapon a gun?..

7) Have you left him/her after living together during the past year?.....

(If you have never lived with him, check here........)

8) Is he/she unemployed?

9) Does he/she threaten to kill you?.............

10) Has he avoided being arrested for domestic violence?

11) Do you have a child that is not his/hers?........

12) Has he/she ever forced you to have sex when you did not wish to do so? ...........

13) Does he/she ever try to choke you?.

14) Does he/she use illegal drugs? By drugs, I mean "uppers" or amphetamines, Meth, speed, angel dust, cocaine, "crack", street drugs or mixtures.

15) Is he/she an alcoholic or problem drinker?..

16) Does he/she control most or all of your daily activities? (For instance: does he tell you who you can be friends with, when you can see your family, how much money you can use, or when you can take the car? .

17) Is he/she violently and constantly jealous of you? For instance, does he say "If I can't have you, no one can"?

18) Have you ever been beaten by him/her while you were pregnant?

19) Has he/she ever threatened or tried to commit suicide?

20) Does he/she threaten to harm your children?

21) Is he/she violent towards your children?.

22) Do you believe he/she is capable of killing you?...

23) Has he/she threaten to kill you?

24) Does he/she follow or spy on you, leave threatening notes or messages, destroy your property, or call you when you don't want him/her to?

25) Have you ever threatened or tried to commit suicide?.

Total "Yes" Answers:

Thank you. Please talk to your nurse, advocate or counselor about

what the Danger Assessment means in terms of your situation

Women were never orally asked about IPV and the nurses at the ED who handed over the questionnaires had no information and possibility to connect a 
patient with a specific answered questionnaire, neither could the researchers. Due to sensitivity of the study, it is difficult to know if any hidden feelings could be triggered, extreme caution was taken to avoid triggering feelings that were deeply hidden. Counselling was offered as a routine, to all women who were seeking care at the ED.

\section{Results}

The 82 abused women's mean age was 43 years (SD 15.2; $\mathrm{r}=18-78$ years) with a total number of 81 children ( $M d 2$ ). Of these 82 women, 58 had a child between the ages of 0 - 18 years old. Of the cases where relationship status could be established; $45 \%(\mathrm{n}=37)$ were married or cohabitating and $40 \%(\mathrm{n}=33)$ were single. $14.6 \%(\mathrm{n}=12)$ of the data was missing.

The marital status i.e. if the woman was married, cohabitating or single, had no significance for increasing or more severe violence. A total of 23 women answered the question about yearly income, showing a low income (mean 211 832SEK). Fifteen (18.3\%) women disclosed that their abuser was unemployed. Stalking and being spied on was experienced by $35.4 \%(\mathrm{n}=29)$ of the women. Of the women (Table 1) 18.3\% $(\mathrm{n}=15)$ stated that the abuser was also violent outside the home and it was found that $19.5 \%(\mathrm{n}=16)$ of the men avoided being arrested by the police and $37.8 \%(\mathrm{n}=31)$ women revealed that their abuser was an alcoholic or had problem with alcohol. Of the women, $18.3 \%(\mathrm{n}=15 \%)$ reported that the abuser was using illegal drugs such as narcotics. A total of $36.6 \%$ $(\mathrm{n}=30)$ of the women felt the men were controlling their daily activities and

Table 1. Abuse women's experience of severe violent threats and severe violence from an intimate partner' relationship (IPV).

\begin{tabular}{|c|c|c|c|c|}
\hline Type of threat/violence & Yes & No & Total & $\begin{array}{c}\text { Women's mean age in } \\
\text { years yes/no }\end{array}$ \\
\hline IPV more frequent in the last year & 6 & 70 & 76 & $49 / 42$ \\
\hline IPV more violent in the last year & 8 & 68 & 76 & $43 / 46$ \\
\hline Threatened with a weapon & 6 & 69 & 75 & $40 / 43$ \\
\hline The abuser tried to choke the women & 16 & 59 & 75 & $37 / 43$ \\
\hline Women threatened to commit suicide & 25 & 51 & 76 & $43 / 43$ \\
\hline The abuser threatened to commit suicide & 16 & 60 & 76 & $35 / 43$ \\
\hline $\begin{array}{l}\text { The partner threatened to } \\
\text { kill the women }\end{array}$ & 23 & 52 & 75 & $43 / 43$ \\
\hline $\begin{array}{l}\text { The women's assumption of } \\
\text { their partners capability to kill }\end{array}$ & 18 & 57 & 75 & $41 / 43$ \\
\hline The abuser was violent against children & 2 & 28 & 30 & $54 / 43$ \\
\hline $\begin{array}{l}\text { The abuser threatened to harm the } \\
\text { children }\end{array}$ & 9 & 60 & 69 & $46 / 43$ \\
\hline Violent outside home & 15 & 55 & 70 & $37 / 43$ \\
\hline
\end{tabular}


$37.8 \%(\mathrm{n}=31)$ women also experienced their partner to be extremely jealous.

\subsection{The Occurrence of Risk Factors and Increased Severity of Violence}

The data showed 31 women, $18-78$ years, answered yes to less than 8 questions showing a danger, and 20 women in the same age group answered to 8 - 13 questions showing increase risk, while 9 women answered yes to 14 - 17 questions between the ages of 31 - 55 years of age showing a severe risk and 4 women ages 41 - 45 answered yes to 18 - 25 questions showing an extreme risk of being violently injured and risk of homicide. 16 of the abused women answered no to all questions on the DAS and two of the abused women did not answer. 7.3\% (n $=6$ ) of the women disclosed that the violence had become more frequent within the last year, while $9.8 \%(\mathrm{n}=8)$ disclosed that the violence had become more severe (Table 1$)$. The study showed $6.1 \%(n=5)$ women tried to leave her abuser during the last year. However, $12.2 \%(n=10)$ of the women disclosed never living with their abuser. There was some significance between the violence increasing in frequency and the severity of violence $(\mathrm{p}=0.000)$.

\subsection{Using a Weapon to Harm the Woman}

The result shows $9.8 \%(\mathrm{n}=8)$ women disclosed a weapon existed in the home such as a knife or gun. While $11 \%(\mathrm{n}=9)$ disclosed that their abuser owned a handgun. It was disclosed (Table 1 ) by six women $(7.3 \%)$ that they had been threatened with a weapon. Of the 82 women $19.5 \%(n=16)$ women answered that a weapon was used to harm them and of these, $4.9 \%(n=4)$ women answered that a gun was used.

\subsection{Threats and Capability of Killing}

As can be seen in Table 1, 22\% $(\mathrm{n}=18)$ of the women reported that their partner was capable of killing them, while $28 \%(\mathrm{n}=23)$ stated that they had been threatened to death and $19.5 \%(\mathrm{n}=16)$ women reported that the partner had tried to choke/strangle them. Significant differences were found between the women's reporting of their abuser's unemployment and the women's thoughts about their abuser's capability of killing $(\mathrm{p}=0.004)$. Of the men who were unemployed $(n=15), 53 \%(n=8)$ were identified as capable of killing the women, while $17 \%(n=10)$ of all the employed $(n=59)$ men were capable. A total of $30.5 \%(n=25)$ women disclosed that they themselves had threatened to or tried to commit suicide. However, sixteen women (19.5\%) reported that the abuser, threatened to commit suicide. The odds for being threatened to death when the abuser was reported to use narcotics and illegal drugs was about 13 times higher compared to the case when the abuser was not using narcotics (OR12.59, CI = $2.74,54.65)$. The same risk was found in those cases where the women reported that the abuser is seen capable of killing and is using narcotics or other illegal drugs compared to those cases where the abuser was not using narcotics $(\mathrm{OR}=$ 13.77; $\mathrm{CI}=2.96,60.78)$. The odds for the abuser threatening with suicide if the 
abuser was jealous compared to not jealous as reported by the women were almost 11 times higher (OR = 10.59 CI; 2.48, 47.68).

\subsection{Pregnancy and Threats to Women and Her Children}

A total of 74 women answered the question about violence during pregnancy. Of these 15 reported to have been pregnant during the time when having a relationship with the abuser while 28 had not been pregnant during the relationship. As many as $41 \%(n=34)$ of the women disclosed being forced to have sex. However, $26.8 \%(n=22)$ women had no children with their abuser and nine women $(11 \%)$ stated that their partner threatened to harm the children. Two women reported that their partner was violent to the children (Table 1). A significant difference was found in women's reporting of the abuser's threats to harm children and using narcotics. More women reported that if the abuser used narcotics the abuser threatened to harm the children (66\%) compared to women's reporting where the abuser did not use narcotics (16\%). The occurrence of violence did not increase if the child was not the abuser's biological child.

\section{Discussion}

In this study, we found that the mean age of the abused women was 43 years, which is in line with the findings by de Boinville [25] and Campbell et al. [5] showing women who reported increased frequency and severity of violence were ages 43 - 49 years. This study shows no significant difference in violence between married and not married women. Of the abused women $18 \%$ reported that their partner was unemployed. A relationship, between unemployment and women's reporting of the partner's ability to kill, was found in the studies by Auchter [26] and Moreno et al. [2]. The yearly mean income among the women was relatively low. However, this must be interpreted with caution as only 23 of the 82 women reported yearly income. Campbell et al. [5] and Dobash et al. [10] found that women's risk of intimate partner homicide and violence is greater among the young and those with low household income. It was found that several women were at risk for being killed, and significant amount were at very high risk which is in line with several findings [5] [10] [26] Our findings demonstrated that $30 \%$ - $40 \%$ of the women reported that their partner spied on them, tried to control their daily activities and were extremely jealous. Research [27] indicates that the most dangerous time for a battered woman is after she ends the relationship. Several men in the study threatened to commit suicide. This may indicate that the violent partner's health is unstable. Previous research [4] [5] [28] disclosed that there is an increased risk of homicide when the man is suicidal. Our findings are in line with other studies [25] [29] showing abused women reported to have threatened to commit suicide and had suicidal thoughts. Several studies [25] [27] [30] [31] highlighted that the risk of suicide is higher among abused women than non-abused, which also puts them at higher risk for mortality. Women (28\%) also reported that their partner threatened to kill them and about $20 \%$ had tried to choke or strangle the women. Such experiences may result in 
PTSD.

The abuser's use of narcotics and illegal drugs seem to be an important risk factor in this study. In this study, the risk for threatening to kill the women was estimated to be 13 times higher if the abuser was reported to use narcotics. This finding is in accordance with The Advocates of Human Rights [27], which concluded that batterers who are heavy drug and alcohol abusers are more likely to kill. The abuse of alcohol and drugs has also been found to be a factor in cases where women kill their batterers. Women are often more afraid when men use drugs and alcohol and are more likely to use violence to protect themselves during an assault. An abuser's prior attempts to choke or strangle the victim are also an indicator of extreme danger. Significantly, more women reported that the partner threatened to harm the children if the person used narcotics. Two women reported that their partner was violent towards their children. These figures may be higher as women may be afraid of reporting violence against children as they might feel afraid of losing custody of the children or that the social welfare authority will take the children from them. This because registered nurses and physicians are, according to the law, obliged to report to the Social welfare authority if children are maltreated [32]. The DAS is a useful and helpful instrument to identify women exposed to violence and by investigating the relationships between risk factors identify at least some questions health care personnel would be recommended to ask. This could provide healthcare professionals a possibility to, in cooperation with the women, develop and activate safety plans and/or caring activities.

It is recommended that each ED should ask or use a questionnaire about experienced or ongoing abuse, type of abuse the women is an object for as well as if the abuse has escalated (danger). The questionnaire used in this study, requires further development with less number of questions and if the women respond yes to have experienced abuse or is ongoing; a strategy for asking more questions should be available. Power analysis was not calculated in the DAS. According to Polit (2004), power analysis is a method of reducing the risk of Type II errors and for estimating their occurrence. Statistical Significance levels in the study was $\mathrm{p}<0.05$, limiting the risk of Type II error. To limit bias in this study and increase trustworthiness, the content of the DAS were checked and reached with professional's research team and together with ED nurses.

\section{Limitations}

Several limitations should be noted. There was some data missing and the CI was found to be wide so the certainty of how big the odds really are is uncertain, it may be lower or higher. The number of participants in the study is small, which also has to be taken into consideration. The DAS could also be developed to contain questions about children who are exposed to or have witnessing violence. This study is one of the first in its kind in Sweden in an emergency setting. This study is showing that it is possible to identify women at extreme risks for being killed or severely injured. However, this also means that health care 
professionals should have support and strategies for dealing with these complex cases and issues. The findings are in accordance to agree with Campbell et al. [5] study concerning lethal violence against women at extreme risk for homicide.

\section{Conclusion}

Women who visited an ED reported to have experienced IPV and were at risk for being killed. The most important risk factors for being threatened to death and violence and threats against children were the partner's use of illegal drugs/ narcotics and threats to commit suicide. Even unemployment could be seen as a risk factor. These may indicate that IPV is closely connected to drug abuse, mental illness or diseases.

\section{Relevance to Clinical Practice}

Health care professional's knowledge about risk factors when caring for abused women is vital for taking adequate actions and develop questionnaires or care actions that may contribute to identifying women at risk. The abuser's use of narcotics and illegal drugs as well as threats to commit suicide and unemployment can be seen as important issues to ask about when caring for women in different health care settings as these can be seen as very important risk factors for increasing violence and risk for homicide.

There are several practical implications in approving the ability to predict severe violence by abusers (i.e. violence likely to result in injury or death). Extreme caution and attention should be given when women disclose that their abuser is suicidal; we believe there is an increased risk of murder-suicide meaning the man kills the woman then kill himself. Healthcare providers should note that it is during the "meeting" with the abused woman one can detect the signs to prevent a murder. Survivors may be reluctant to disclose their victimization whether to law enforcement or to family and friends for a variety of reasons including shame, embarrassment, fear of retribution from perpetrators, or a belief that they may not receive support from law enforcement.

\section{Funding}

This study has been funded by Institute of Health and Care Sciences, Sahlgrenska Academy University of Gothenburg, Sweden and Nordic Holistic Care.

\section{References}

[1] Lawoko, S., Sanz, S., Helström, L., and Castren, M. (2011) Screening for Intimate Partner Violence against Women in Healthcare Sweden: Prevalence and Determinants. ISRN Nursing, 1-7. https://doi.org/10.5402/2011/510692

[2] Moreno, G.C., Guedes, A. and Knerr, W. (2012) Understanding and Addressing Violence. World Health Organization (WHO), Geneva, Switzerland, WHO/RHR/ 12.35. http://apps.who.int/iris/bitstream/10665/77433/1/WHO_RHR_12.35_eng.pdf

[3] The Swedish National Council for Crime Prevention Homicide in Finland, The Netherlands and Sweden (2012) A First Study on the European Homicide Monitor Data. The National Research Institute of Legal Policy and The Institute for Criminal 
Law and Criminology at Leiden University, Research Report 2011:15, Stockholm, Sweden.

[4] Rying, M. (2001) Acts of Lethal Violence against Women in Intimate Relationships. National Council of Crime Prevention (BRÅ), BRÅ-Report 2001:11, Stockholm.

[5] Campbell, C.J., Webster, D., Kaziol-McLain, J., Block, C.R, Campbell, D., Curry, M., Gary, F. McFarlene, J, Sachs, C., Sharps, P., Ulrich, Y. and Wilt, S.A. (2003) Assesing Risk Factors for Intimate Partner Homicide. National Institute of Justice Journal Issue, 250, 14-19.

[6] Sabri, B., Stockman, J.K., Campbell, J.C., O’Brien S., Campbell, D., Callwood, G.B. and Hart-Hyndman, G. (2014) Factors Associated with Increased Risk for Lethal Violence in Intimate Partner Relationships among Ethnically Diverse Black Women. Violence and Victims, 29, 719-741. https://doi.org/10.1891/0886-6708.VV-D-13-00018

[7] Browne, A., Williams, K.R. and Dutton, D.G. (1998) Homicide between Intimate Partners, In: Smith, M.D. and Zahn, M., Eds., Homicide: A Sourcebook of Social Research, Sage, Thousand Oaks, CA, 149-164.

[8] United Nations (2011) Violence against Women. Seretary General's Campaign UNITE-To End Violence against Women. Department of Public Information, DPI/2546A, New York.

http://endviolence.un.org/pdf/pressmaterials/unite_the_situation_en.pdf

[9] Abrahams, N., Mathews, S., Jewkes, R., Martin, L.J. and Lombard, C. (2012) Every Eight Hours: Intimate Femicide in South Africa 10 Years Later! South African Medical Research Council, Research Brief.

[10] Dobash, R.E., Dobash, R.P., Cavanagh, K. and Medina-Ariza, J. (2007) Lethal and Non-Lethal Violence against an Intimate Female Partner: Comparing Male Murderers with Non-Lethal Abusers. Violence against Women, 13, 329-353. https://doi.org/10.1177/1077801207299204

[11] Hedtke, K.A., Ruggiero, K.J., Fitzgerald, M.M., Zinzow, H.M., Saunders, B.E., Resnick, H.S., et al. (2008) A Longitudinal Investigation of Interpersonal Violence in Relation to Mental Health and Substance Use. Journal of Consulting and Clinical Psychology, 76, 633-647. https://doi.org/10.1037/0022-006X.76.4.633

[12] Johnson, D.M., Delahanty, D.L. and Pinna, K. (2008) The Cortisol Awakening Response as a Function of PTSD Severity and Abuse Chronicity in Sheltered Battered Women. Journal of Anxiety Disorders, 22, 793-800. https://doi.org/10.1016/j.janxdis.2007.08.006

[13] Katz, L.S., Snetter, M.R., Robinson, A.H., Hewitt, P. and Cojucar, G. (2008) Holographic Reprocessing: Empirical Evidence to Reduce Posttraumatic Ognitions in Women Veterans with PTSD from Sexual Trauma and Abuse. Psychotherapy: Theory, Research, Practice, Training, 45, 186-198.

https://doi.org/10.1037/0033-3204.45.2.186

[14] Wilcox, H.C., Storr, C.L. and Breslau, N. (2009) Posttraumatic Stress Disorder and Suicide Attempts in a Community Sample of Urban American Young Adults. Archives of General Psychiatry, 66, 305-311. https://doi.org/10.1001/archgenpsychiatry.2008.557

[15] Messing, J.T., Amanor-Boadu,Y., Cavanaugh, C.E, Glass. N. and Campbell, J.C. (2013) Culturally Competent Intimate Partner Violence Risk Assessment for Immigrant Women. Social Work Research, 37, 263-275. https://doi.org/10.1093/swr/svt019

[16] Carretta, C.M. (2008) Domestic Violence: A Worldwide Exploration. Journal of Psychosocial Nursing and Mental Health Services, 46, 26-35. 
https://doi.org/10.3928/02793695-20080301-02

[17] Sundborg, E.M., Saleh-Stattin, N., Wändell, P. and Törnkvist, L. (2012) Nurses' Preparedness to Care for Women Exposed to Intimate Partner Violence: A Quantitative Study in Primary Health Care. BioMed Central Nursing, 11, 1-11.

[18] Bengtsson-Tops, A., Markström, U. and Levin, B. (2005) The Prevalence of Abuse in Swedish Female Psychiatric Users, the Perpetrators and Places Where Abuse Occurred. Nordic Journal of Psychiatry, 59, 504-510. https://doi.org/10.1080/08039480500360732

[19] Oram, S., Trevillion, K., Feder, G. and Howard, L.M. (2013) Prevalence of Experiences of Domestic Violence among Psychiatric Patients: A Systematic Review. British Journal of Psychiatry, 202, 94-99. https://doi.org/10.1192/bjp.bp.112.109934

[20] Pratt-Eriksson, D., Dahlborg-Lyckhage, E., Lind, C., Sundberg, K. and Bergbom, I. (2015) Identifying Lifetime and Occurrence of Intimate Partner Violence among Women in Sweden Seeking Emergency Care. Open Journal of Nursing, 5, 548-557. https://doi.org/10.4236/ojn.2015.56058

[21] Stenson, K., Heimer, G., Lund, C., Nordström, M.L. Sarinnen, H. and Wenker, A. (2003) Lifetime Prevalence of Sexual Abuse in a Swedish Pregnant Population. Acta Obstetricia et Gynecologica Scandinavica, 82, 529-536. https://doi.org/10.1034/j.1600-0412.2003.00111.x

[22] Campbell, J. (2004) Danger Assessment. Johns Hopkins University, School of Nursing. A Modified Version for Swedish Population (Ingegerd Bergbom, Elisabeth Dahlborg Lyckhage, Darcia Pratt-Eriksson Copyright 2006 Sahlgrenska Academy, Gothenburg University, Institute for Health and Care Sciences).

[23] Campbell, J.C. (1994) Assessing Dangerousness. Sage, Newbury Park. The Reliability and Factor Structure of the Index of Spouse Abuse with African-American Battered Women. Violence and Victims, 9, 259-274.

[24] Polit, D. and Beck, C.T. (2004) Nursing Research Principles and Methods. $7^{\text {th }}$ Edition, Lippincott Williams \& Wilkins, Philadelphia.

[25] de Boinville, M. (2013) Screening for Domestic Violence in Healthcare Settings. ASPE Policy Brief. https://aspe.hhs.gov/report/screening-domestic-violence-health-care-settings

[26] Autcher, B. (2010) Men Who Murder Their Families: What the Research Tells Us. NIJ Journal, No. 266, NCJ 230412.

[27] The Advocates for Human Rights (2006) Lethality Assessments. Stop the Violence against Women. A Project of the Advocates of Human Rights. February 1, Minneapolis. http://www.stopvaw.org/lethality_assessments

[28] Hart, B. (2010) Battered Women-Suicide. National Domestic Violence Fatality Review Initiative (NDVFRI), Winter 3-14.

[29] Dillon, G., Hussain, R., Loxton, D. and Rahman, S. (2013) Mental and Physical Health and Intimate Partner Violence against Women. A Review of the Literature. International Journal of Family Medicine, 2013, 313909.

[30] Golding, J. (1999) Intimate Partner Violence as a Risk Factor for Mental Disorders: A Metaanalysis. Journal of Family Violence, 14, 99-132.

[31] Dutton, M., Kaltman. S., Goodman, L., Weinfurt, K. and Vankos, N. (2005) Patterns of Intimate Partner Violence: Correlates and Outcomes. Violence Victims, 20, 483497. https://doi.org/10.1891/vivi.2005.20.5.483

[32] Socialstyrelsen (2001) The Social Services Act. The Swedish National Board of Health and Welfare, Socialstyrelsen, Stockholm. Ministry of Health and Social affairs. 
Submit or recommend next manuscript to SCIRP and we will provide best service for you:

Accepting pre-submission inquiries through Email, Facebook, LinkedIn, Twitter, etc. A wide selection of journals (inclusive of 9 subjects, more than 200 journals)

Providing 24-hour high-quality service

User-friendly online submission system

Fair and swift peer-review system

Efficient typesetting and proofreading procedure

Display of the result of downloads and visits, as well as the number of cited articles Maximum dissemination of your research work

Submit your manuscript at: http://papersubmission.scirp.org/

Or contact ojn@scirp.org 